\title{
The Impact of Job-Specific Training on Short-Term Worker Performance: Evidence from a Field Experiment*
}

\author{
Preliminary and Incomplete
}

Elizabeth Lyons ${ }^{\dagger}$

September 8, 2016

\begin{abstract}
Remote and short-term work arrangements are increasingly common despite the limited incentives they provide for acquiring firm-specific knowledge. This paper examines the importance and cost-effectiveness of firm-specific training for remote contract workers using evidence from a field experiment conducted in an East African insurance firm that offers two-month employment contracts for its salespeople. Findings show that firm-specific training significantly increases firm revenue, but that this effect is concentrated among higher ability workers. Training has no impact on worker retention, and offering workers financial or competitive input-based incentives has no impact on these findings, or on observed worker investment in firm-specific training. These results demonstrate that high ability temporary workers may be willing to invest in firm-specific human capital without additional incentives, and that firm performance is significantly improved as a result. Implications for temporary work contracts are discussed.
\end{abstract}

JEL Classification: J24, J49, M53, O33

*Eddy Chebelyon provided excellent project management and research assistance. I thank Iddo Dror, Nathan Jensen, Craig McIntosh, Andrew Mude, Brenda Wandera, Deborah Wyburn, and seminar participants at Harvard Business School and the International Livestock Research Institute for valuable input and feedback. I gratefully acknowledge funding support from The Center on Global Transformation at UC San Diego. This study is included in the AEA RCT Registry (AEARCTR-0001515).

† School of Global Policy and Strategy, University of California, San Diego, 9500 Gilman Drive, MC 0519 La Jolla, CA 92093-0519. lizlyons@ucsd.edu. 


\section{Introduction}

Short-term and remote work arrangements have increased drastically over the past two decades.

For instance, the U.S. Government Accountability Office estimated that contingent workers accounted for 40.4\% of employed workers in 2010, up from 35\% in 2006 (Murray and Gillibrand, 2015). Similarly, the percentage of American workers who work remotely at least some of the time, many of whom are not permanent employees, increased from $7.9 \%$ in 1997 to $9.5 \%$ in 2010 (Mateyka et al., 2010). ${ }^{1}$ These changes are driven in part by advances in ICT which are facilitating distance communication and lowering the transaction costs of hiring and looking for work (Agrawal et al., 2015).

While the current discussion surrounding the rise of non-standard work arrangements at times suggests that the growth in short-term and remote work is boundless ${ }^{2}$, an important barrier to this growth may be the need for workers to invest in organization-specific knowledge. In particular, incentives and opportunities for acquiring firm-specific knowledge among these workers may be limited (e.g. Becker, 1962; Lazear, 2009). Moreover, temporary workers may be lower skilled than permanent workers (Booth et al., 2002) potentially introducing additional barriers to training (Autor, 2001). Remote work may further exacerbate the ability for short-term workers to acquire firm-specific knowledge by making tacit knowledge transfer more difficult (Jaffe et al., 1993). Understanding the extent to which short-term workers are willing to invest in firm-specific knowledge and how this investment affects firm performance is critical for firm management of these

\footnotetext{
${ }^{1}$ Temporary and remote employment may be of even greater importance in lower income countries in which the share of permanent employment is relatively small and transportation and distribution is challenging (Dihel, 2011; International Labor Office, 2015).

${ }^{2}$ For instance, The Economist (2015) article "The future of work: There's an app for that" writes "...the now ubiquitous platform of the smartphone to deliver labour and services in a variety of new ways will challenge many of the fundamental assumptions of 20th-century capitalism, from the nature of the firm to the structure of careers."
} 
work arrangements, and for understanding the development of the contract labor market and the on-demand economy more generally.

This paper aims to contribute to a better understanding of firm-specific knowledge acquisition among short-term, remote workers by presenting evidence from a field experiment run among short-term sales people employed by an insurance firm in Northern Kenya. Specifically, I test whether giving these workers the option to invest in firm-specific training affects their performance, retention, and subsequent firm earnings, and how this varies with monetary and competition-based incentives to invest in the training. To overcome difficulties associated with causally linking human capital investment to performance outcomes (Card, 1999), I randomly assigned three versions of a smart phone training application to the insurance sales agents and compare their performance with a control population who did not receive the application. All three versions had the same training content, and, in addition to this content, one version offered small monetary rewards for successful completion of training content, and another offered game features including leaderboards and performance-based digital badges. The population of workers in this study are hired for two-month periods to sell insurance for drought related livestock losses, and paid commission for their sales. Turnover among these agents is quite high; between the sales window prior to the experiment of the experiment and period of the experiment, only $38 \%$ of the sales agents were retained. The sales agency model they work under is similar to the sales agency model employed by many American organizations, including insurance firms (e.g. Regan and Tennyson, 1996). It is also a distribution model that is frequently employed in Sub-Saharan Africa to overcome difficulties associated with infrastructure development and human capital shortages firms face when trying to serve rural 
markets (Dihel, 2011).

Findings from my experiment show that offering short-term workers access to firm-specific training significantly increases firm revenue. Relative to sales agents who did not have access to the training, those who did increased their sales by over KSH 15,000 on average ${ }^{3}$. Compared to the sample average sales of $\mathrm{KSH} 20,619$ per agent, this is an almost 75\% increase. Moreover, when a non-winsorized measure of sales is used, the intention to treat estimate demonstrates that access to training almost doubles sales per agent relative to the sample mean. Providing input-based financial and competitive incentives for investment in the training has no effect on observed investment or on the performance impact of giving agents access to firm-specific training. Consistent with existing evidence that the benefits of offering training differs by worker ability (e.g. Autor, 2001), I find that providing the option to invest in firm-specific training improves firm outcomes by improving the performance of high ability sales agents and has no performance effects on lower ability agents. This is consistent with theoretical evidence that workers who expect to gain from their investment in training will invest in it (Becker, 1962). Given the short time horizon over which workers in my study expect to earn returns, only those with very high expected short-run earnings from specific training, for instance, as a result of their relatively high absorptive capacity or their complementary skills, may be willing to invest in it.

Combined, results from this study provide support for the importance of firm- and productspecific knowledge among short-term workers. They suggest that firm-specific knowledge may be under-invested in by temporary workers and under-provided to them by firms, but that reducing this knowledge gap may also be relatively easy. More broadly, these findings suggest that if the need

\footnotetext{
${ }^{3}$ At the time of the study, KSH 100 was equivalent to approximately 1 USD.
} 
for investment in transaction-specific knowledge is properly managed, it may not severely hinder the growth in short-term and remote employment. Moreover, as ICT is facilitating the growth in these work arrangements in other ways, it may also provide an important means for transmitting this knowledge.

This paper proceeds as follows. Section 2 reviews related literature and presents theoretical motivation for the experiment design; section 3 presents the experiment design; section 4 describes and summarizes the data; section 5 presents the empirical results from the experiment; and section 6 summarizes and concludes.

\section{Motivating Literature}

This paper contributes to the literature on training within firms, and in particular, how the provision of firm-specific training affects firm performance. In addition, by considering how competitive and direct payments affect investment in training, this paper also contributes to literature on incentives

for human capital investment, and for production more generally. In this section, I consider each of these streams of literatures in turn.

\subsection{Training in Organizations}

Training in firms can take on two forms: general skills training that workers can make use of in other firms, or specific training that is only useful to workers while they are working within the focal firm. These types of training have distinct implications for firm and worker incentives to invest in them, and these incentives vary depending on the expected length of workers' tenure. In 
"Investment in Human Capital: A Theoretical Analysis", Becker (1962) develops a theory of on the job training in which firms provide training when future expected costs are reduced or future expected returns are increased by the training sufficiently to justify its up-front cost. Perfectly general training is never worth investing in for the firm because the training will increase workers' wages by the same amount increase in their marginal product because the knowledge is equally valuable in other firms. As a result, the costs of general training investments are incurred by workers and not by firms. In contrast, a worker's market wage would not increase as a result of perfectly specific training because the training would not increase her marginal product in any other firm. As a result, workers are not willing to incur the costs of perfectly specific training. Importantly, because the returns a firm or worker earns from firm-specific training depends on how long the worker remains with the firm, firms may not be willing to incur the costs of specific training either. Therefore, Becker's theory predicts that workers and firms split the costs of firmspecific training and both invest the amount that they expect to receive in returns. ${ }^{4}$ Therefore, the likelihood that workers will invest in firm-specific training falls as their expected tenure with the firm falls because the window for them to earn returns from their investment falls.

Several subsequent theoretical papers support Becker (1962)'s predictions about the role that job turnover plays in how we expect firms and workers to invest in firm-specific human capital. For instance, Booth and Chatterji (1989)'s theory demonstrates that redundancy payments can be justified by firm requirements for workers to incur some of the costs of investing in firm-specific training. Carmichael (1983) similarly develops a theory of promotion ladders as a contracting tool

\footnotetext{
${ }^{4}$ Consistent with Becker (1962)'s seminal work, this paper considers a setting in which the costs of firm-specific training are shared by workers and the firm. As section 3 highlights, the firm develops the training material and pays workers commissions which allows workers to share in the pay-off from training, and workers invest their own unpaid time in the training.
} 
to encourage optimal investment in firm-specific knowledge, and Jovanovic (1979) predicts that as workers accumulate firm-specific human capital, they become less likely to leave the firm by choice.

Empirical evidence on how job length affects investment in firm-specific human capital provides general support for these theories. For instance, Loewenstein and Spletzer (1997), Lynch (1991), and Parsons (1972) all show a negative correlation between investment in firm-specific capital and job exits. Most relevant for this paper, prior literature has also shown a negative relationship between the need for specific human capital and the use of temporary workers (DavisBlake and Uzzi, 1993), and between firm investment in training and temporary work contracts (Booth et al., 2002). Moreover, temporary workers are of lower expected ability, and thus may benefit less from training even if they were to invest (Autor, 2001; Booth et al., 2002). To my knowledge, existing empirical work on training among temporary workers considers the firm's hiring and training decisions rather than the worker's decision to invest in specific training. By considering whether workers on short-term contracts are willing to invest time in firm-specific training when it is provided to them, this paper fills this gap in the literature.

Training within firms may also be impacted by whether or not work is done remotely. For instance, existing evidence suggests that on the job training occurs through both formal and informal knowledge transfer (Tracey et al., 1995). Knowledge transferred through less formal means may be less codifiable and more tacit (e.g. Reagans and McEvily, 2003), making it harder to transfer over geographic distances (Jaffe et al., 1993). This paper contributes to our knowledge of remote worker training by studying how the provision of training impacts the performance of a population 
of outside sales people with little to no face time with their managers.

The evidence on whether investments in firm specific human capital translate into performance improvements is sparse. Theoretically, firms will not incur the costs to train workers in specific human capital if they do not anticipate a return from it. However, whether firm-specific investment pays off for firms in practice is less clear. ${ }^{5}$ In particular, existing evidence is mixed with some studies showing a positive correlation between firm-specific training and performance (e.g. Collins and Smith, 2006), and others showing no correlation (e.g. Jones et al., 2012). In general, however, the evidence is sparse and, to my knowledge, there is no evidence on how providing training for temporary workers impacts firm performance.

\subsection{Direct Incentives for Investment in Human Capital}

As the previous sub-section made clear, individuals invest in human capital when they expect the returns to their investment will pay off by increasing their earnings. However, recent experimental evidence suggests people may also respond to direct incentives for their investment. For instance, Levitt et al. (2016) provide evidence that financial rewards for achieving set standards along multiple dimensions improves short term outcomes for high school freshman who were close to reaching the standards before the incentives were introduced. Leuven et al. (2010) also find positive impacts of financial rewards for student achievement on performance, however the effect is restricted to high ability students; low ability students perform worse in the face of the financial incentives which may suggest a dampening of intrinsic motivation due to extrinsic rewards. Kremer et al.

\footnotetext{
${ }^{5}$ A related stream of literature considers investments in professional training. For instance, there is empirical evidence that professional training leads to better outcomes for entrepreneurs (e.g. De Mel et al., 2014; Lyons and Zhang, 2016) and that vocational training improves short run outcomes for unemployed workers (Hirshleifer et al., 2015). Also related is Macchiavello et al. (2015) who analyze the impact of providing training to garment factory workers in Bangladesh. They find that the training significantly improves the performance of female supervisors.
} 
(2009) find positive performance effects of financial incentives in the form of scholarships among students and no evidence of a crowding out of intrinsic motivation. Hirshleifer (2015) finds that providing financial incentives for inputs has a positive impact on student outcomes, and a larger effect than providing financial incentives for outputs. In contrast, Fryer (2011) does not find robust evidence that financial incentives for investment in reading and for performance have an affect on student outcomes.

The setting presented in this paper is distinct from those presented in the aforementioned papers. The subjects in my study are workers, not students, and their investment in training is unlikely to be beneficial to them outside of their current contract. Moreover, workers have financial incentives to invest in training if they believe it will lead to increased performance, and therefore, higher commission payments. However if, as Hirshleifer (2015) suggests, individuals are present-biased, input-based financial incentives may increase investment in training particularly as commissions are paid only after the 2 month sales window. Given the evidence from Levitt et al. (2016) and Leuven et al. (2010) that the effects of financial incentives vary with individual ability, we may be most likely to observe an impact of these rewards on worker investment in training among those who expect to do well enough on the training to receive the reward, and most likely to observe a performance effect of these rewards on workers who are skilled enough that they expect to receive the input-based reward but less skilled than those who perform very well in their job in the absence of the training.

In addition to financial incentives for training investment, this paper tests whether offering competition-based incentives affects how short-term workers invest in specific training. Theo- 
retically, competitive, or relative performance, compensation may increase investment in training particularly when monitoring is difficult as it is in the case of managing remote workers ( $\mathrm{O}^{\prime} \mathrm{Keeffe}$ et al., 1984). By highlighting relative performance, gamification through leaderboards and badges has been argued to be a cost effectiveness means for increasing motivation among students, workers, and customers (Hamari et al., 2014). However, evidence from the computer science literature suggests that the effects of competition that results from gamification on learning may be mixed. For instance, some studies found that it has zero or negative impacts on the effectiveness of education (e.g. Amriani et al., 2013; Hanus and Fox, 2015), and others have found significant positive impacts of gamification on educational outcomes (e.g. Bellotti et al., 2013; Ibanez et al., 2014). Importantly, as with financial incentives for training inputs, the impact of competitive incentives on performance is unlikely to be homogeneous across worker ability. In particular, if workers are not of similar abilities, these incentives may reduce investment in training among the weakest workers (Nalebuff and Stiglitz, 1983)

Given that the time frame over which short-term workers expect to benefit from specific training is small, their incentives in the absence of input-based incentives may be limited. Therefore, understanding whether providing them with input-based incentives can increase training investment has important implications for the management of these labor contracts and for understanding the role of input-based incentives for investment in human capital more generally. 


\section{Experimental Design}

In order to provide causal evidence on whether offering firm-specific training to short-term remote workers, I ran a field experiment in which I randomly assigned the option to invest in firm-specific training through a mobile training application to insurance sales agents in Northern Kenya. This design allows me to control for selection into training while still allowing me to test whether workers are willing to invest in it. In this section, I describe my research setting, the population of agents in my study, the experimental treatment groups, and the provision of training to agents in the treatment groups.

\subsection{Research Setting}

I ran my experiment in Northern Kenya in collaboration with Index Based Livestock Insurance (IBLI), a project group that operates out of the International Livestock Research Institute (ILRI) in Nairobi, Kenya, and Takaful Insurance of Africa (TIA), the largest Sharia compliant insurance company in East and Central Africa. TIA distributes and underwrites IBLI in Northern Kenya.

IBLI is an index-based insurance product that covers pastoralists in arid and semi arid regions against risk of drought related livestock losses. ${ }^{6}$ TIA sells IBLI to Kenyan pastoralists using an outside sales-agent model in which agents are selected in part based on their literacy, and their relationship to their local community. They are tasked with selling IBLI within their communities for a two month sales windows. Sales windows occur twice a year (from the beginning of January to the end of February, and from the beginning of August to the end of September), and there is

\footnotetext{
${ }^{6}$ For a detailed description of IBLI, please refer to (Chantarat et al., 2013).
} 
substantial agent turnover between windows. In the sales window covered by the experiment, TIA was providing IBLI in 6 counties in Northern Kenya; Garissa, Isiolo, Mandera, Marsabit, Moyale, and Wajir. Each county is includes a number of divisions, the majority of which are covered by TIA (ranging from 4 to 16 per county) ${ }^{7}$, and each division is assigned one lead agent and several sub-agents. Figure 1 presents a map of the counties and divisions included in this study color coded by treatment assignment.

The pastoralists who are the targets of IBLI are largely unfamiliar with and leery of the product, and with insurance in general. IBLI sales agents surveyed during the January-February, 2015 sales window were ten times more likely to report that that poor pastoralist education about insurance was a bigger barrier to their sales than the cost of the insurance product was. IBLI, like all insurance products, is complex, and mis-informing customers about what to expect from the coverage is illegal and can lead to further mistrust of the product within communities (Matul et al., 2013). Unlike many other insurance products, IBLI provided by TIA is Sharia compliant and pay-outs are based on an index tied to the Normalized Differential Vegetation Index (NDVI). Therefore, knowledge about IBLI and about TIA as a provider of Sharia compliant insurance is likely to be important for agents to develop and maintain sales.

\subsection{Study Population}

All lead and sub-agents employed by TIA to sell IBLI during the August-September, 2015 sales window are included in my sample. Lead agents are tasked with finding and training sub-agents in addition to selling the product. To help them in these tasks, lead agents attend a three day in-person

\footnotetext{
${ }^{7}$ Divisions not covered by TIA in these counties are considered security threats due to the presence of the Al Shabab militant group.
} 
training camp where they learn about IBLI, TIA, and selling in general. Sub-agents are small business owners, for instance, retail store owners or M-PESA ${ }^{8}$ agents, who are recruited because they have frequent contact with potential customers. Although they have sales experience as store owners, anecdotal evidence from conversations with TIA employees and lead agents suggests that they are frequently semi-literate or illiterate and have primary educations on average. Lead agents are more educated than sub-agents, on average they have some post-secondary education, but like sub-agents, they frequently have additional income earning activities and do not consider selling IBLI to be their career.

Agents are assigned to sell in the division they live in, however, they are free to sell in other divisions as well. TIA employs local workers first, because they speak the local dialects and are more likely to be trusted by the pastoralists in their community, and second, because it is difficult to recruit non-local workers to relocate to these relatively under-developed and remote regions (Government of Kenya, 2011). All agents are paid a commission, and lead agents also receive a small retainer payment at the beginning of the sales window.

\subsection{Experimental Treatments}

To test short-term workers are willing to invest in firm-specific knowledge, and how the provision of this knowledge affects firm performance, I randomly assigned sales agents into one of three treatment groups or a control group. As Figure 2 demonstrates, agents in all three treatment groups receive access to a mobile training application that provides training modules, quizzes, and frequently asked questions on TIA and the insurance product they are selling. One treatment group

\footnotetext{
${ }^{8}$ M-PESA is a mobile money transfer service used extensively in Kenya.
} 
was sent a version of the training application that offers agents the opportunity to be awarded phone credit for good performance on the module quizzes. Going forward, I refer to this as the incentive group. The second treatment group was sent a version of the training application that includes game features (specifically, a leader board and badges for participation and good performance on the module quizzes). Going forward, I refer to this as the competition group. The third treatment group does not receive any additional content on their training application. Going forward, I refer to this as the basic group. Agents in the control group did not receive access to the training application.

Agents in the incentive group were awarded KSH 250 in phone credit for each quiz for which they got at most one question wrong. Although agents can take each quiz as many times as they like, they can only be awarded phone credit once per quiz, and only for their first attempt at the quiz. Therefore, these agents could earn up to KSH 1750 from the application (about 17 USD at the time of the study). Agents in the competition group had access to a leader board on their applications that showed them how they ranked relative to all other agents (including those not in the competition group). Only agent numbers were listed on the leader board so as to protect agents' privacy. Agents in this group could also receive digital badges for completing each quiz and separately for performing well on each quiz (i.e. getting at most one question wrong).

To avoid agents in the control knowing about the training application or gaining access to the content, and to avoid agents in one treatment group learning about other versions of the application and potentially becoming upset by the differences or becoming aware of a potential study, randomization occurred at the division level. Agents were not aware of the study, nor were they aware that 
there were different versions of the application or that some agents did not receive access to the application.

\subsection{Training Provision}

Training was provided to agents in the treatment groups through an Android application developed by contracted computer programmers in a collaboration with TIA and IBLI. TIA began providing all agents with Android smart phones in the January-February, 2015 sales season to allow agents to record all their sales on a sales transaction application developed for IBLI sales agents. This roll-out confirmed the willingness and ability of agents to use smart phone applications.

The training application was developed to provide simple, direct, and concise statements about the insurance product, and TIA. These statements are each under one of 7 training modules. At the conclusion of each training module, agents can complete a quiz on the content covered in the corresponding module. The application also includes a frequently asked questions section that agents can refer to when they are selling. This section includes 17 questions and answers which are meant to address confusion agents in previous sales windows had when selling the product. Sample screen shots of the application are provided in Figure 3.

Training applications were provided to agents in the treatment groups through SMS five days before the beginning of the August-September, 2015 sales window. SMS messages included download instructions, a link to the application, and depending on which treatment group agents were in, a message about the application. In the basic treatment group, agents were told they could use this application to help them better understand IBLI and potentially improve their sales. In the in- 
centive treatment group, agents were told the same thing but were also told they could earn phone credit by performing well on the quizzes in the training application. In the competition treatment group, agents were told what agents in the basic group were told and were also told that they could see how their performance on the training application quizzes compares with other agents, and receive badges on the application for participating in the training and performing well on the quizzes. Over the next four days, each agent in the treatment groups was contacted by phone by a researcher at IBLI and/or by TIA county coordinators who are permanent employees to determine whether they had received the app and been able to download it. In some cases, because of poor network in some areas, efforts to reach agents by phone continued after the sales window had begun.

\section{Data \& Estimation Strategy}

\subsection{Overview of the Data}

My experiment was run in August and September of 2015 and included all agents and sub-agents employed by TIA to sell IBLI during this time. In total, my sample includes 295 agents, 241 of whom are sub-agents and 54 of whom are lead agents. Agents are divided into 54 divisions across 6 counties in Northern Kenya. The control group includes 11 divisions and a total of 73 agents, the basic treatment group includes 15 divisions and 73 agents, the incentive treatment group includes 13 divisions and 69 agents, and the competition treatment group includes 15 divisions and 80 agents.

For agents in the treatment groups, I collected data on their use of the application, includ- 
ing whether they used the application, how frequently they used it, and their quiz scores. This data is transmitted to the application server when agents have cell phone network. Due to some technical difficulties, use data is an imperfect measure of training engagement. ${ }^{9}$ I collected sales performance data on all agents in my sample at the conclusion of the sales window during which the experiment was run. This includes the sum of premiums they collected, the total value of the insured animals in the insurance policies they sold, and the total number of animals they insured. I also collected prior sales data for all agents who sold IBLI for TIA during the previous sales window. I measure prior sales as equal to zero if agents were not previously employed by TIA. To measure longer term impacts of training, I collected data on whether or not each agent was retained by TIA to sell IBLI in the subsequent sales window, as well as sales data from the subsequent sales window for all agents who were retained in addition to totals for each division.

In addition to information on agents' sales, locations, and training application investment, I have gender information for agents in my sample. Lead agents attend face-to-face training and are given a test at the beginning and at the end of training to determine how much they know about IBLI and TIA coming into the training, and how much they learned from the training. I collected training test scores for the 46 lead agents who attended this training and took these tests in preparation for the sales window covered by my experiment. ${ }^{10}$ In addition, I have survey data on educational and demographic backgrounds for 33 lead of the 54 lead agents. These surveys were conducted by ILRI during lead agent training for the sales window that preceded the window covered by the experiment presented in this paper and, as a result, only include the agents who

\footnotetext{
${ }^{9}$ Specifically, some phones were wiped before agents entered regions with network coverage.

${ }^{10}$ Four agents took the pre-training quiz but not the post-training quiz. The remaining 4 agents were either unable to attend training due to travel hazards or ill during the time of the tests.
} 
were retained for the following sales window. ${ }^{11}$

Summary statistics of agents in my sample are presented in Table 1. Panel A presents summary statistics of agent characteristics which show that the majority of agents are male, and there are many more sub-agents than there are lead agents. In addition, the average age of lead agents in the survey data is about 30 years old, and their average level of education is some post-secondary education. Panel B presents summary statistics on agent investment in the training application. The sample used in this panel is restricted to those agents who are in the treatment groups (and are thus able to invest in the training). The statistics demonstrate that $18 \%$ of agents in the treatment groups were observed making any investment in the training application, and that on average, they spent more time in the frequently asked questions section than the training module section. The average length of time agents were observed spending on the application is about 2 minutes with a maximum of 2.5 hours. ${ }^{12}$ Panel C present summary statistics of sales and retention outcomes. Agents collected about $\mathrm{KSH} 41,000$ in premiums, and that those who were retained from the previous sales window increased their sales by about KSH 53,000. Sales in the subsequent sales window appear to have fallen among those agents who were retained to about KSH 11,000 on average. Among agents in divisions that TIA continued to actively sell in during the subsequent sales window, $41 \%$ were retained.

It's important to note that sales outcomes are across agents are very skewed; $78 \%$ of agents having zero sales and the top ten percentile have over KSH 40,000 in sales. This is consistent with sales data from other settings. For instance, in a recent industry study of over 500,000 sales people,

\footnotetext{
${ }^{11}$ Efforts to run a similar survey for all agents included in the experiment were unsuccessful.

${ }^{12}$ Among agents who did invest time in the training application, the average time they were observed spending on the application was 10 minutes.
} 
$74 \%$ of the sample was identified as "mediocre or worse" (Kurlan, 2014). According to the Bureau of Labor Statistics, the bottom $10 \%$ of insurance sales people, including those who earn base salaries, earn about $\$ 26,000$ per year whereas the top $10 \%$ earn over $\$ 120,000$ per year (Bureau of Labor Statistics, 2015). ${ }^{13}$ Moreover, the BLS reports that sales people paid on commission have among the largest within-occupation earnings differences (Torpey, 2015).

To verify the randomness of treatment assignment within my sample, I compare agent characteristics across my treatment and control groups and present these summary statistics in Table 2. The statistics show that agents look similar across groups on all variables. However, although the difference is not significant, agents in the control group have lower prior sales on average than those in the treatment group. I did not have access to this information until after the experiment was run and, as a result, did not correct for this difference in the randomization process. To ensure that it is not driving my estimated findings, I will control for prior sales in my regression analyses.

Figure 4 compares outcomes for those who did not receive access to the training application to those who did. The Figure reports the p-values from Theorem 3.1 in List et al. (2016) to account for the multiple outcomes being tested. As this chart demonstrates, access to the training application significantly increases agent sales, and agent retention.

Given that randomization occurred at the division level, and that prior experience differs between the control and treatment groups, analyzing whether these results hold when controlling for these differences is important.

\footnotetext{
${ }^{13}$ In contrast, there is only a $\$ 65,000$ difference between the $10 \%$ and $90 \%$ percentile earners among HR managers who have a similar median income as insurance agents do.
} 


\subsection{Empirical Strategy}

To analyze whether or not giving short-term workers access to firm-specific training impacts firm outcomes, I estimate the intention to treat using the following linear model:

$$
Y_{i}=\alpha+\beta \text { TrainingTreatment }_{i}+\delta \text { Agent Type }_{i}+\gamma \text { PreviousSales }_{i}+\theta \text { County }_{i}+\varepsilon_{i},
$$

where $Y_{i}$ is equal to agent $i$ 's sales measured as total premiums collected or agent $i$ 's retention measured as an indicator for whether or not the agent was retained by the firm for the subsequent sales window, Training Treatment ${ }_{i}$ is equal to one if agent $i$ received access to the training appli-

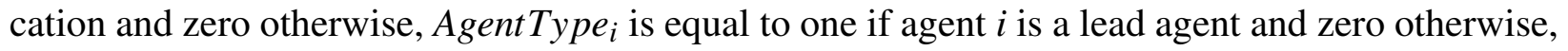
PreviousSales $_{i}$ is equal to agent $i$ 's previous sales window premiums collected, and Count $y_{i}$ are county fixed effects. Standard errors are clustered by division. Agent type is included as a control because it is likely to affect both sales and training investment. To account for extreme outliers in sales outcomes, I employ a $90 \%$ winsorization so that sales outcomes above the 95 th percentile are set equal to those at the 95 th percentile. I focus on agent retention as well as sales performance because, given prior theoretical and empirical evidence, investment in specific human capital may alter the agents' expected return from continuing with the firm relative to moving on to other work.

In addition to investigating whether access to the training impacts firm outcomes, I consider whether providing incentives for the training differentially impacts firm outcomes by estimating the following equation: 


$$
\begin{array}{r}
Y_{i}=\alpha+\beta_{1} \text { BasicTreatment }_{i}+\beta_{2} \text { Incentive Treatment }_{i}+\beta_{3} \text { CompetitionTreatment }_{i}+ \\
\delta \text { AgentType }_{i}+\gamma \text { PreviousSales }_{i}+\theta \text { Count }_{i}+\varepsilon_{i},
\end{array}
$$

where Basic Treatment $_{i}$ is equal to 1 if agent $i$ is in the basic treatment group and zero otherwise, IncentiveTreatment $_{i}$ is equal to 1 if agent $i$ is in the incentive treatment group and zero otherwise, CompetitionTreatment $t_{i}$ is equal to 1 if agent $i$ is in the competition treatment group and zero otherwise, and all other variables are as in equation 1. Standard erros are clustered by division. I also consider how the incentive and competition treatments affect investment in training relative to the basic treatment group by estimating a similar equation as 2 but with training take-up as the dependent variable, basic treatment as the excluded group, and the sample restricted to agents in the treatment groups.

In this experiment, the local average treatment effect estimates are likely biased because the treatments were assigned at the division level, and I expect spillovers from compliers to noncompliers within divisions either because agents within the same division share knowledge gained from the training, or because those who invest in the training alter the sales environment in their division. ${ }^{14}$ I investigate whether there is any evidence of localized spillovers from having at least one agent in a division invest in the specific training.

\footnotetext{
${ }^{14}$ For instance, if sales go up as a result of an agent who invests in training, more people in a division may become familiar with the product because are more likely to have friends or family who have purchased it and, thus, may be more likely to purchase from any agent.
} 


\section{Results}

In this section, I begin by presenting intention to treat estimates from equation 1 followed by those from equation 2 to determine whether giving agents access to training impacted their sales and whether the returned to the firm for the subsequent sales season, and how these results vary depending on whether agents received an incentive for investment in the training. I follow this analysis by considering how incentives affected investment in training. I provide robustness checks of these results to determine whether my results are affected by how sales outcomes are measured and by using a Poisson estimating model rather than an OLS model. Once the primary experimental findings have been established, I explore how they vary with agent ability measured by whether or not the agent is a lead agent and by whether or not the agent has prior sales experience.

\subsection{Main Results}

Estimates from equation 1 are presented in Table 3. Columns 1 and 3 present the estimates from regressions without controls for agent type, prior sales, or county fixed effects, and columns 2 and 4 present the estimated results with these controls included. Columns 1 and 2 demonstrate that including the covariates does decrease the size and statistical significance of the effect of training access on total sales, and that even with the inclusion of controls, access to training increases the sales premiums collected by over KSH 15,000 per agent and this estimate is significant at the $10 \%$ level. Relative to the sample mean sales premiums collected, this is about a $75 \%$ increase in sales per agent. Given that the upfront investment required for the firm to provide the training application was quite low and that the most time any agent spent investing in it was about 2.5 hours, this seems 
like a high return from firm-specific training.

Columns 3 and 4 also demonstrate that the inclusion of covariates decreases the economic and statistical significance of access to training on agent retention. Although the effect of training on retention is positive, with the inclusion of controls for agent type, prior sales, and county fixed effects, it is statistically insignificant.

As expected, agent type is significantly related to both sales and retention. In particular, lead agents have significantly higher sales and are more likely to work for the firm during the subsequent sales window. I explore whether agent type relates to the effectiveness of the treatment in subsection 5.2. Going forward, for simplicity I will not report the covariate coefficients.

Estimates from equation 2 are presented in Table 4 and show that providing input-based incentives for investment in specific training does not significantly increase sales outcomes or retention. The coefficient on the incentive treatment indicator reported in column suggests an economically large impact on sales, however, it is only significant at the $15 \%$ level. The coefficient on the competition treatment is economically quite small and insignificant. Consistent with input-based incentives not improving the effects of access to training on outcomes, Table 5 demonstrates that

observed investment in training was not affected by financial or competition-based incentives. This suggests that the output-based incentives given by commission payments may be sufficient for encouraging investment in firm-specific training.

\subsubsection{Robustness to Sales Measure \& Poisson Estimation}

As described in section 4, sales are very skewed across agents with the majority having no sales and the top sales people having over KSH 1 million in sales. Therefore, determining whether 
my results are robust to different measures of sales is important for verifying the validity of my findings and for exploring how sales are being affected by specific training availability.

Table 6 reports estimated effects of training access on sales outcomes. Column 1 reports the estimates when total premiums collected is not winsorized. Not surprisingly, the effect size is much larger (more than double the effect with winsorization) and suggests that access to training almost doubles sales relative to the sample mean. Column 2 reports the estimated effect of training access on whether or not an agent makes any sales at all. These results suggest that access to specific training does not appear to improve firm outcomes by moving agents who would not otherwise sell to positive sales. Column 3 reports the estimated effect of training access on whether or not an agent is in the 90th percentile of sales outcomes. This estimate demonstrates that access to training affects agents who are already selling by increasing their sales. Section 5.2 will further explore heterogeneity in the intention to treat estimates by agent ability.

\subsection{Results by Agent Type}

Given the existing theoretical and empirical evidence on firm-specific human capital investment, the effects of offering training, and of offering incentives to invest in training may differ by agent ability. I consider two measures of agent ability; first, whether or not an agent is a lead agent, and second, whether or not an agent had sales in the previous sales window. ${ }^{15}$ The former measure allows for new agents to be of high ability, however, dimensions other than ability also differ between lead and sub-agents including how they are paid. The latter measure does not allow for new agents to be high ability.

\footnotetext{
${ }^{15}$ Both sub-agents and lead agents have positive prior sales. In particular, $27 \%$ of sub-agents and $52 \%$ of lead agents have prior sales.
} 
Figure 5 reports mean premiums collected by agents in the control and the treatment group across these two measures of ability. The Figure reports the p-values from Theorem 3.1 in List et al. (2016) to account for the multiple sub-groups being considered. Mean comparisons demonstrate that, although sales are higher in the treatment group than in the control across all agent types, the effect of the treatment is only statistically significant among the higher ability agent types. Table 7 reports similar estimates from a regression with the agent ability measures interacted with the training access treatment. Consistent with the mean comparisons reported in Figure 5, these estimates show that both lead agents and agents with prior sales experience appear to benefit more from the training treatment than sub-agents and those without prior experience.

This finding is consistent with the finding reported in column 3 of Table 6 that suggests giving short-term workers access to specific training improves firm outcomes by improving the highest performers. This is consistent with an interpretation of agent investment in specific training as concentrated among those who are higher ability, and therefore, may have higher expectations about their returns from human capital investment. It is also consistent with higher ability agents being more able to absorb the information provided in the training application. Use data provides evidence in support of both these explanations. In particular, while lead agents are significantly more likely to be observed investing in the training, those with prior sales experience are not.

I also consider whether these financial and competition-based input-based incentives affect high and low ability agents differently. I estimate equation 2 by agent ability and report the results in Table 8. These results demonstrate that incentives to not appear to impact whether or not giving agents access to specific training leads to better sales outcomes. High ability agents in the treatment 
group have better sales outcomes whether or not they are given input-based incentives to invest in the training and lower ability agents do not appear to significantly benefit from being in the treatment group whether or not they are given input-based incentives to invest in the training. Somewhat interestingly, columns 1 and 3 provide suggestive but insignificant evidence that, as theoretical evidence would suggest, lower ability agents in the competition group seem to have worse outcomes than the control group.

\section{Conclusion}

As the growth in short-term contract work continues, understanding whether these contracts are limited by the lack of incentives for idiosyncratic investments they provide, and whether managers can overcome this barrier is also becoming increasingly important both for workers and organizations. This paper contributes to this understanding by testing the returns to providing firm-specific training to short-term workers using a field experiment run with Northern Kenyan insurance sales agents.

Results from the experiment show that the providing workers with a low cost means of investing in firm-specific knowledge significantly increases firm revenue and agent commission payments even when agents' expected tenure is very short. Collected premiums increased by about $75 \%$ relative to the sample mean among agents who had access to the training. Importantly, these gains were concentrated among higher ability agents; high ability agents who received access to firm-specific training more than doubled their sales relative to those who did not. In contrast, lower ability agents who were given access to the training did not significantly increase their sales. In ad- 
dition, I find no impact of input-based incentives for specific training investment on the likelihood of investment, or on sales outcomes. Despite existing evidence that investment in firm-specific human capital increases worker tenure (Loewenstein and Spletzer, 1997; Lynch, 1991; Parsons, 1972), I do not find robust evidence that receiving access to the training increases worker retention.

Combined, these results suggest that investment in firm-specific knowledge does have a large impact on worker performance even among workers with short-term contracts. Moreover, overcoming incentive barriers to idiosyncratic investment when short-term workers are employed may be feasible at relatively low costs particularly when workers are high ability and expect to gain from their investments. Organizations who rely on temporary employment contracts may therefore benefit from providing specific training, and may not need to provide input-based incentives for investment in it when expected output-based incentives are large enough.

It is important to note that these findings are based on a population of workers who may not have had the same opportunities or incentives to invest in human capital prior to the study as workers in more economically developed regions. The majority of workers were sub-agents who did not receive any formal training from the insurance firm and many of whom have at most a primary school level of education. On the one hand then, it is not surprising that these lower ability workers benefited less from specific training because they likely have a lower capacity for absorbing the information (Autor, 2001). On the other hand, we may have expected these agents to benefit relatively more from the training because they were starting from a lower base knowledge (Card, 1993). In settings where all short-term workers are relatively educated, firm- 
specific training may benefit lower ability workers as well if they expect to earn sufficient returns from investing in it. Another potentially important boundary condition on the magnitude of the estimated results is the quality of management these workers were subject to. Evidence from Bloom et al. (2016) suggests that developing country firms have worse management practices than firms elsewhere and that this affects their performance. If insurance agents in my study were being poorly managed, they may have benefited more from firm-specific training than they would have if they were being well managed because other managerial interventions may partially substitute for this knowledge. ${ }^{16}$ Consistent with (Bloom et al., 2013), my findings that relatively standard managerial interventions can have large impacts on firms in developing countries.

This paper contributes to organizational and labor economics literature by identifying the value of providing firm-specific training to short-term workers. In particular, this paper builds on theoretical literature that considers the role of expected length of employment on incentives for specific training investment (e.g. Becker, 1962). My findings provide support for the theoretical prediction that high enough expected short-run earnings from the training can compensate for a short earnings horizon. It also contributes to empirical literature on the performance implications of specific training (Collins and Smith, 2006; Jones et al., 2012) and of professional and employer-sponsored training more generally (De Mel et al., 2014; Hirshleifer et al., 2015; Lyons and Zhang, 2016; Macchiavello et al., 2015). Furthermore, this paper contributes to literature on incentives for human capital investment (Fryer, 2011; Levitt et al., 2016; Leuven et al., 2010; Kremer et al., 2009) by demonstrating that input-based incentives do not appear impact investment in training in the

\footnotetext{
${ }^{16}$ For instance, regular performance feedback, like that of online feedback mechanisms for digital labor market workers, may provide another means for gathering idiosyncratic knowledge.
} 
presence of high-powered output-based incentives.

Practically, the results presented in this paper suggest that the growth in temporary work arrangements may not be hindered by firm-specific knowledge requirements. Specifically, if temporary workers expect that their investment in firm-specific human capital will be sufficiently valuable for their short-term earnings relative to their cost of investing in it, the incentives for acquiring this knowledge should lead these workers to do so. Therefore, managers may be able to facilitate this knowledge acquisition by offering the content in a manner that does not require overly expensive investments from workers, by ensuring that the offered content can have a positive impact on their performance, and by ensuring that their pay is also tied to their performance. Moreover, managers should ensure that specific training content and expected returns take into account the ability of temporary workers.

\section{References}

Agrawal, Ajay, John Horton, Nicola Lacetera, and Elizabeth Lyons, "Digitization and the Contract Labor Market," Economic Analysis of the Digital Economy, 2015, p. 219.

Amriani, Afifa, Alham F Aji, Andika Y Utomo, and Kasiyah M Junus, "An empirical study of gamification impact on e-Learning environment," in "Computer Science and Network Technology (ICCSNT), 2013 3rd International Conference on” IEEE 2013, pp. 265-269.

Autor, David H, "Why do temporary help firms provide free general skills training?," Quarterly Journal of Economics, 2001, pp. 1409-1448.

Becker, Gary S, "Investment in human capital: A theoretical analysis," The journal of political economy, 1962, pp. 9-49.

Bellotti, Francesco, Riccardo Berta, Alessandro De Gloria, Elisa Lavagnino, Alessandra Antonaci, Francesca Maria Dagnino, and Michela Ott, "A gamified short course for promoting 
entrepreneurship among ICT engineering students," in "2013 IEEE 13th International Conference on Advanced Learning Technologies” IEEE 2013, pp. 31-32.

Bloom, Nicholas, Benn Eifert, Aprajit Mahajan, David McKenzie, and John Roberts, "Does Management Matter? Evidence from India," The Quarterly journal of economics, 2013, 128 (1), $1-51$.

_ , Raffaella Sadun, and John Van Reenen, "Management as a Technology?," Harvard Business School Strategy Unit Working Paper, 2016, (16-133).

Booth, Alison and Monojit Chatterji, "Redundancy payments and firm-specific training," Economica, 1989, pp. 505-521.

Booth, Alison L, Marco Francesconi, and Jeff Frank, “Temporary jobs: stepping stones or dead ends?," The economic journal, 2002, 112 (480), F189-F213.

Bureau of Labor Statistics, "May 2015 National Occupational Employment and Wage Estimates," Database, United States Department of Labor: Bureau of Labor Statistics 2015.

Card, David, "Using geographic variation in college proximity to estimate the return to schooling," Technical Report, National Bureau of Economic Research 1993.

_ , "The causal effect of education on earnings," Handbook of labor economics, 1999, 3, 18011863.

Carmichael, Lorne, "Firm-specific human capital and promotion ladders," The Bell Journal of Economics, 1983, pp. 251-258.

Chantarat, Sommarat, Andrew G Mude, Christopher B Barrett, and Michael R Carter, "Designing index-based livestock insurance for managing asset risk in northern Kenya," Journal of Risk and Insurance, 2013, 80 (1), 205-237.

Collins, Christopher J and Ken G Smith, "Knowledge exchange and combination: The role of human resource practices in the performance of high-technology firms," Academy of management journal, 2006, 49 (3), 544-560.

Davis-Blake, Alison and Brian Uzzi, "Determinants of employment externalization: A study of temporary workers and independent contractors," Administrative Science Quarterly, 1993, pp. 195-223.

Dihel, Nora, "Beyond the Nakumatt Generation: Distribution Services in East Africa," The World Bank: Africa Trade Policy Notes, 2011, (26).

Fryer, Roland G, "Financial Incentives and Student Achievement: Evidence from Randomized Trials," The Quarterly Journal of Economics, 2011, 126 (4), 1755-1798.

Government of Kenya, "Vision 2030 Development Strategy for Northern Kenya and other Arid Lands," Report 2011. 
Hamari, Juho, Jonna Koivisto, and Harri Sarsa, "Does gamification work?-a literature review of empirical studies on gamification," in "2014 47th Hawaii International Conference on System Sciences” IEEE 2014, pp. 3025-3034.

Hanus, Michael D and Jesse Fox, "Assessing the effects of gamification in the classroom: A longitudinal study on intrinsic motivation, social comparison, satisfaction, effort, and academic performance," Computers \& Education, 2015, 80, 152-161.

Hirshleifer, Sarojini, "Incentives for Effort or Outputs? A Field Experiment to Improve Student Performance," Technical Report, Working Paper 2015.

_, David McKenzie, Rita Almeida, and Cristobal Ridao-Cano, "The impact of vocational training for the unemployed: experimental evidence from Turkey," The Economic Journal, 2015.

Ibanez, Maria-Blanca, Angela Di-Serio, and Carlos Delgado-Kloos, "Gamification for engaging computer science students in learning activities: A case study," IEEE Transactions on Learning Technologies, 2014, 7 (3), 291-301.

International Labor Office, "Non-standard forms of employment," Report, Conditions of Work and Equality Department 2015.

Jaffe, Adam B, Manuel Trajtenberg, and Rebecca Henderson, "Geographic localization of knowledge spillovers as evidenced by patent citations," the Quarterly journal of Economics, 1993, pp. 577-598.

Jones, Derek C, Panu Kalmi, and Antti Kauhanen, "The effects of general and firm-specific training on wages and performance: evidence from banking," Oxford economic papers, 2012, $64(1), 151-175$.

Jovanovic, Boyan, "Firm-specific capital and turnover," The Journal of Political Economy, 1979, pp. 1246-1260.

Kremer, Michael, Edward Miguel, and Rebecca Thornton, "Incentives to learn," The Review of Economics and Statistics, 2009, 91 (3), 437-456.

Kurlan, Dave, “The Modern Science Behind Sales Force Excellence,” Technical Report, Objective Management Group, Inc. 2014.

Lazear, Edward P, "Firm-Specific Human Capital: A Skill-Weights Approach," Journal of Political Economy, 2009, 117 (5), 914-940.

Leuven, Edwin, Hessel Oosterbeek, and Bas Klaauw, "The effect of financial rewards on students' achievmenet: Evidence from a randomized experiment," Journal of the European Economic Association, 2010, 8 (6), 1243-1265.

Levitt, Steven D, John A List, and Sally Sadoff, "The effect of performance-based incentives on educational achievement: Evidence from a randomized experiment," Technical Report, National Bureau of Economic Research 2016. 
List, John A, Azeem M Shaikh, and Yang Xu, "Multiple hypothesis testing in experimental economics,” Technical Report, National Bureau of Economic Research 2016.

Loewenstein, Mark A and James R Spletzer, "Delayed formal on-the-job training," Industrial \& labor relations review, 1997, 51 (1), 82-99.

Lynch, Lisa M, "The role of off-the-job vs. on-the-job training for the mobility of women workers," The American Economic Review, 1991, 81 (2), 151-156.

Lyons, Elizabeth and Laurina Zhang, "Does Entrepreneurship Training Lead to Entrepreneurship?," Technical Report 2016.

Macchiavello, Rocco, Andreas Menzel, Atonu Rabbani, Christopher Woodruff et al., "Challenges of Change: An Experiment Training Women to Manage in the Bangladeshi Garment Sector," Technical Report, Competitive Advantage in the Global Economy (CAGE) 2015.

Mateyka, Peter J., Melanie A. Rapino, and Liana Christin Landivar, "Home-Based Workers in the United States: 2010,” Report, U.S. Census Bureau 2010.

Matul, Michal, Aparna Dalal, Ombeline De Bock, and Wouter Gelade, "Why people do not buy microinsurance and what can we do about it," ILO Microinsurance paper, 2013, 20.

Mel, Suresh De, David McKenzie, and Christopher Woodruff, "Business training and female enterprise start-up, growth, and dynamics: Experimental evidence from Sri Lanka," Journal of Development Economics, 2014, 106, 199-210.

Murray, Patty and Kirsten Gillibrand, "ContingentWorkforce: Size, Characteristics, Earnings, andBenefits,” Report, U.S. Government Accountability Office 2015.

Nalebuff, Barry J and Joseph E Stiglitz, "Prizes and incentives: towards a general theory of compensation and competition," The Bell Journal of Economics, 1983, pp. 21-43.

O'Keeffe, Mary, W Kip Viscusi, and Richard J Zeckhauser, "Economic contests: Comparative reward schemes," Journal of Labor Economics, 1984, pp. 27-56.

Parsons, Donald O, "Specific human capital: An application to quit rates and layoff rates," Journal of political economy, 1972, 80 (6), 1120-1143.

Reagans, Ray and Bill McEvily, "Network structure and knowledge transfer: The effects of cohesion and range," Administrative science quarterly, 2003, 48 (2), 240-267.

Regan, Laureen and Sharon Tennyson, "Agent discretion and the choice of insurance marketing system," Journal of Law and Economics, 1996, pp. 637-666.

The Economist, “The Future of Work: There's an app for that,” Technical Report 2015.

Torpey, Elka, "Same occupation, different pay: How wages vary," Report, United States Department of Labor: Bureau of Labor Statistics 2015. 
Tracey, J Bruce, Scott I Tannenbaum, and Michael J Kavanagh, "Applying trained skills on the job: The importance of the work environment.," Journal of applied psychology, 1995, 80 (2), 239. 


\section{Tables and Figures}

Figure 1: Treatment Groups by Region

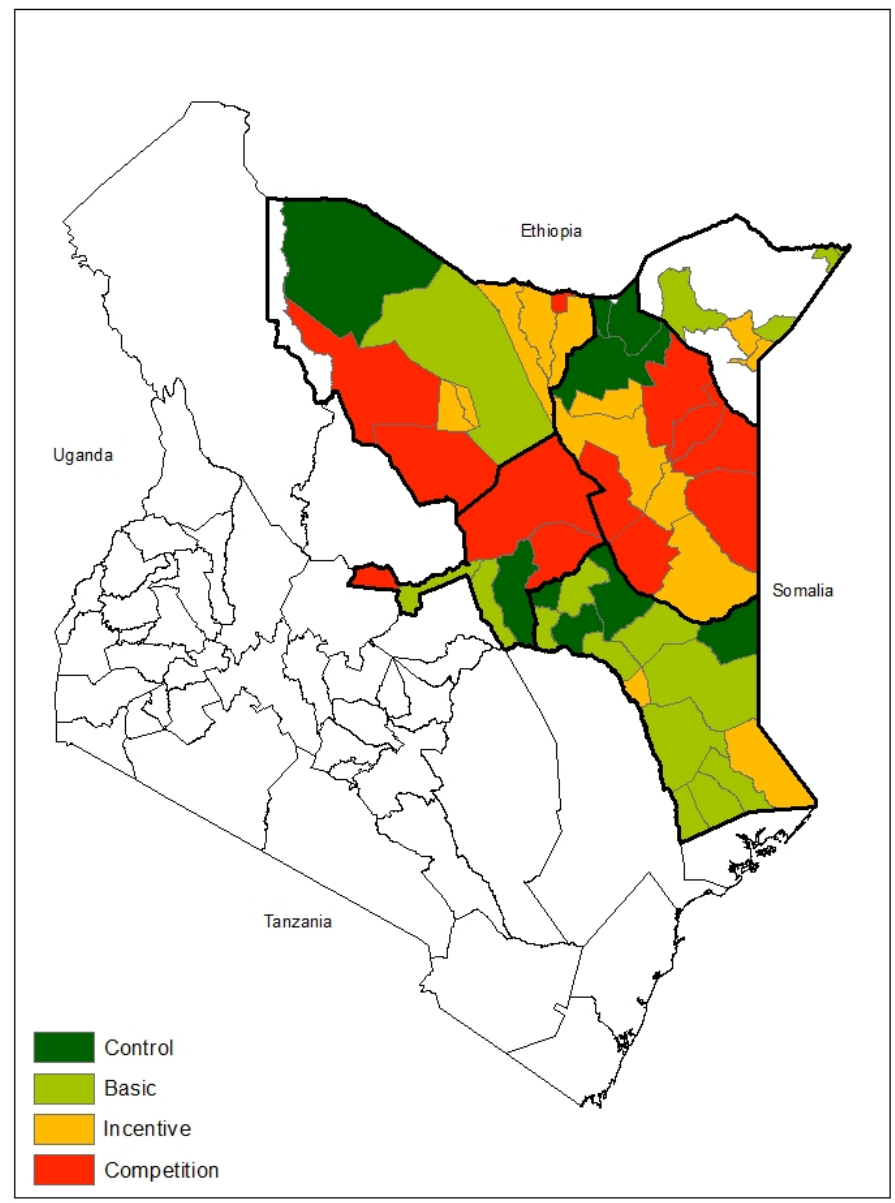

Notes: This map presents the regions in which sales agents operate in Kenya. Thick black lines divide counties included in the study, and divisions are colored by the treatment group they are in. Non-colored regions are not covered by the sales agents. 
Figure 2: Treatment Assigments

\begin{tabular}{lcccc} 
& $\begin{array}{c}\text { Control } \\
\text { Group }\end{array}$ & $\begin{array}{c}\text { Basic Treatment } \\
\text { Group }\end{array}$ & $\begin{array}{c}\text { Incentive } \\
\text { Treatm ent Group }\end{array}$ & $\begin{array}{c}\text { Competition } \\
\text { Treatment Group }\end{array}$ \\
\hline $\begin{array}{l}\text { Mobile Training } \\
\text { Application Access }\end{array}$ & $\mathrm{X}$ & $\mathrm{X}$ & $\mathrm{X}$ \\
\hline $\begin{array}{l}\text { Phone Credit for Good } \\
\text { Performance }\end{array}$ & & $\mathrm{X}$ & \\
\hline $\begin{array}{l}\text { Leaderboards \& Digital } \\
\text { Badges for Participation } \\
\text { and Good Performance }\end{array}$ & & & $\mathrm{X}$
\end{tabular}

Table 1: Agent Summary Statistics

\begin{tabular}{|c|c|c|c|c|c|}
\hline & Mean & Std. Dev. & Min & Max & No. of Obs. \\
\hline \multicolumn{6}{|l|}{ Panel A: Agent Characteristics } \\
\hline Lead Agent & 0.183 & 0.387 & 0 & 1 & 295 \\
\hline Male & 0.893 & 0.310 & 0 & 1 & 290 \\
\hline $\begin{array}{l}\text { Previous Window Sales } \\
\text { (Premiums in KSH) }\end{array}$ & $12,636.373$ & $33,595.346$ & 0 & 326,932 & 295 \\
\hline Pre-Training Quiz & 6.560 & 2.476 & 1 & 13 & 50 \\
\hline Post-Training Quiz & 8.413 & 2.093 & 3 & 13 & 46 \\
\hline Age & 29.879 & 8.392 & 20 & 52 & 33 \\
\hline Highest level of education & 4.273 & 0.761 & 3 & 5 & 33 \\
\hline \multicolumn{6}{|l|}{ Panel B: Agent Training Investment } \\
\hline Any Training Investment & 0.177 & 0.381 & 0 & 1 & 222 \\
\hline Number of Unique Application Uses & 2.261 & 5.949 & 0 & 36 & 222 \\
\hline Seconds on FAQ & 58.820 & 592.591 & 0 & $8,143.52$ & 222 \\
\hline Seconds on Modules & 43.180 & 161.150 & 0 & $1,462.47$ & 222 \\
\hline Seconds on Application & 102.000 & 692.722 & 0 & $9,140.250$ & 222 \\
\hline \multicolumn{6}{|l|}{ Panel C: Agent Outcomes } \\
\hline Livestock Insured (TLUs) & 35.916 & 149.823 & 0 & $1,268.4$ & 295 \\
\hline Premiums Collected (KSH) & $41,156.70$ & $175,663.30$ & 0 & $1,577,986$ & 295 \\
\hline Total Value of Insured (KSH) & $502,823.05$ & $2,097,525.48$ & 0 & $17,800,000$ & 295 \\
\hline Retained for Next Window & 0.409 & 0.493 & 0 & 1 & 230 \\
\hline $\begin{array}{l}\text { Subsequent Window Sales } \\
\text { (Premiums in KSH) }\end{array}$ & $11,210.38$ & $45,318.62$ & 0 & 270,297 & 96 \\
\hline $\begin{array}{l}\text { Change in Sales from Previous Window } \\
\text { (Premiums in KSH) }\end{array}$ & $53,368.36$ & $264,673.42$ & $-326,932$ & $1,504,291$ & 113 \\
\hline
\end{tabular}




\section{Figure 3: Training Application Images}

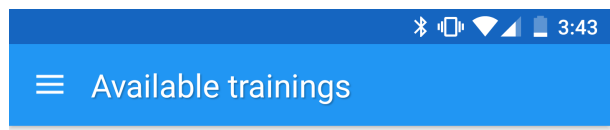

What is Index-Based Takaful?

What is IBLT?

What are the benefits of IBLT?

What is the Forage Scarcity Index?

How are policy holder contributions calculated?

What is a pay-out?

Who is Takaful Insurance of Africa (TIA)?

This module contains a lesson and a quiz.

You may go through the lesson and then take the quiz, or skip the lesson and go straight to the quiz.

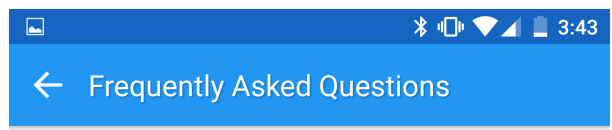

? Which livestock can be protected by IBLT?

? How long does an IBLT policy insure me for?

?hy is the tabaru (premium) in my Division different from the premium of other Divisions?

? What risk is covered by IBLT?

? If I buy a policy, how many pay-outs am I eligible for?

? How does the satellite work?

? Will my tabaru by refunded?

? How do I get updates on what the index is?

? What is the trigger value?

? When is the index triggered?

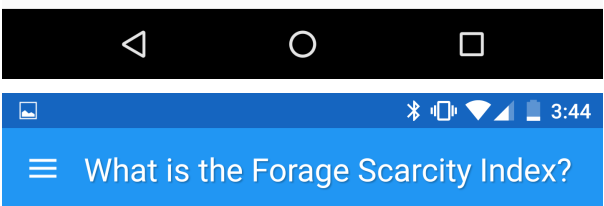

The forage scarcity index is the indicator that determines whether or not IBLT policy holders receive a pay-out

○

$\square$
SKIP

\section{$\triangleleft$}

O 
Table 2: Agent Characteristics by Treatment Group

\begin{tabular}{lccccc}
\hline \hline Agent Characteristics & Control & Basic & Incentive & Competition & p-value $^{+}$ \\
\hline Lead Agent & 0.151 & 0.205 & 0.188 & 0.188 & 0.856 \\
& $(0.36)$ & $(0.407)$ & $(0.394)$ & $(0.393)$ & \\
Male & 0.877 & 0.909 & 0.894 & 0.885 & 0.868 \\
& $(0.331)$ & $(0.290)$ & $(0.310)$ & $(0.322)$ & \\
Previous Window Sales & $5,382.81$ & $13,657.26$ & $14,038.16$ & $17,114.65$ & 0.172 \\
(Premiums in KSH) & $(35,518.596)$ & $(34,761.3)$ & $(28,261.01)$ & $(45,035.078)$ & \\
Pre-Training Quiz & 6.273 & 6.385 & 7.077 & 6.462 & 0.858 \\
& $(3.036)$ & $(2.063)$ & $(2.100)$ & $(2.876)$ & \\
Post-Training Quiz & 8.455 & 7.75 & 8.900 & 8.615 & 0.614 \\
& $(2.659)$ & $(1.658)$ & $(2.132)$ & $(1.981)$ & \\
Age & 25.333 & 28.9 & 31.5 & 32.556 & 0.389 \\
& $(4.412)$ & $(6.707)$ & $(8.484)$ & $(11.337)$ & \\
Highest level of education & 4.667 & 4.2 & 4.125 & 4.222 & 0.585 \\
& $(0.516)$ & $(0.789)$ & $(0.641)$ & $(0.972)$ & \\
\hline
\end{tabular}

Notes: Standard deviations are in parentheses. * significant at 10\%; ** significant at 5\%; *** significant at $1 \%$

${ }^{+}$Test for equality of four group means using multivariate analysis of variance

Table 3: Effect of Access to Training on Sales and Agent Retention

\begin{tabular}{lcccc}
\hline & $(1)$ & $(2)$ & $(3)$ & $(4)$ \\
& \multicolumn{2}{c}{ Sales Premiums Collected } & \multicolumn{2}{c}{ Agent Retention } \\
\hline Training Access Treatment & $20,762.08^{* * *}$ & $15,219.70^{*}$ & $0.172^{* *}$ & 0.068 \\
& $(7,617.21)$ & $(9,022.23)$ & $(0.083)$ & $(0.064)$ \\
Agent Type & & $59,851.54^{* * *}$ & & $0.531^{* * *}$ \\
& & $(11,976.60)$ & & $(0.059)$ \\
Previous Window Sales & & 0.099 & & $0.000^{* *}$ \\
& & $(0.109)$ & & $(0.000)$ \\
County Fixed Effects & No & Yes & No & Yes \\
Observations & 295 & 295 & 230 & 230 \\
R-squared & 0.022 & 0.255 & 0.021 & 0.258 \\
Mean dep var & 20,619 & 20,619 & 0.409 & 0.409
\end{tabular}

Notes: An observation is a sales agent. Standard errors clustered by division are reported in parentheses. Sales Premiums Collected are in Kenyan Shillings. The measure of sales premiums used in this analysis limits the influence of extreme outliers with a $90 \%$ winsorization. Agent Retention is equal to one if the agent works for the firm during the subsequent sales season, and zero otherwise. The sample in columns 2 and 3 is restricted to the counties in which the firm actively sold in the subsequent sales window. * significant at $10 \%$; ** significant at $5 \%$; *** significant at $1 \%$ 
Figure 4: Agent Outcomes Comparison

\begin{tabular}{|c|c|c|c|}
\hline \multicolumn{4}{|l|}{60000} \\
\hline & & $\begin{array}{c}\text { Theorem } 3.1 \\
0.046\end{array}$ & \\
\hline 50000 & & & $\begin{array}{c}\text { Theorem } 3.1 \\
0.058\end{array}$ \\
\hline \multicolumn{4}{|l|}{40000} \\
\hline \multicolumn{4}{|l|}{30000} \\
\hline 20000 & $\begin{array}{c}\text { Theorem } 3.1 \\
0.000\end{array}$ & & \\
\hline \multicolumn{4}{|l|}{10000} \\
\hline D & Any App Use*100000 & Premiums (KSH) & Retention*100000 \\
\hline & & - Control $\backsim$ Treatment & \\
\hline
\end{tabular}


Table 4: Effect of Incentives to Invest in Training on Sales and Agent Retention

\begin{tabular}{lcccc}
\hline & $(1)$ & $(2)$ & $(3)$ & $(4)$ \\
& \multicolumn{2}{c}{ Sales Premiums Collected } & \multicolumn{2}{c}{ Agent Retention } \\
\hline Basic Treatment & $8,275.28$ & $13,093.09 *$ & 0.099 & 0.022 \\
& $(5,117.56)$ & $(7,931.13)$ & $(0.089)$ & $(0.095)$ \\
Incentive Treatment & $33,721.23$ & $27,607.88$ & $0.174^{*}$ & 0.091 \\
& $(20,775.04)$ & $(19,098.57)$ & $(0.098)$ & $(0.103)$ \\
Competition Treatment & $20,979.017 * * *$ & $5,412.249$ & $0.249^{* *}$ & 0.151 \\
& $(7,195.37)$ & $(11,119.37)$ & $(0.103)$ & $(0.133)$ \\
Controls & No & Yes & No & Yes \\
County Fixed Effects & No & Yes & No & Yes \\
Observations & 295 & 295 & 230 & 230 \\
R-squared & 0.043 & 0.269 & 0.034 & 0.263 \\
Mean dep var & 20619 & 20619 & 0.409 & 0.409 \\
\hline
\end{tabular}

Notes: An observation is a sales agent. Standard errors clustered by division are reported in parentheses. Sales Premiums Collected are in Kenyan Shillings. The measure of sales premiums used in this analysis limits the influence of extreme outliers with a $90 \%$ winsorization. Agent Retention is equal to one if the agent works for the firm during the subsequent sales season, and zero otherwise. The sample in columns 2 and 3 is restricted to the counties in which the firm actively sold in the subsequent sales window. * significant at $10 \%$; ** significant at $5 \%$; *** significant at $1 \%$

Table 5: Effect of Incentives to Invest in Training Training Investment

\begin{tabular}{lc}
\hline & Any Training Investment \\
\hline Incentive Treatment & 0.030 \\
& $(0.082)$ \\
Competition Treatment & 0.012 \\
& $(0.101)$ \\
Observations & 222 \\
R-squared & 0.426 \\
Mean dep var & 0.306 \\
\hline
\end{tabular}

Notes: An observation is a sales agent. Standard errors clustered by division are reported in parentheses. Controls for prior sales, agent type, and county fixed effects are included. The dependent variable is equal to one if the agent was observed investing in training, and zero otherwise. The sample is restricted to agents who had access to the training application. * significant at $10 \%$; $* *$ significant at $5 \%$; *** significant at $1 \%$ 
Table 6: Robustness of Main Effect to Sales Measure

\begin{tabular}{lccc}
\hline & $(1)$ & $(2)$ & $(3)$ \\
& Non-Winsorized Sales & Any Sales & Sales $>90$ th Percentile \\
\hline Training Access Treatment & $37,401.804^{*}$ & 0.010 & $0.067^{*}$ \\
& $(22,673.465)$ & $(0.072)$ & $(0.038)$ \\
& & & \\
Observations & 295 & 295 & 295 \\
R-squared & 0.122 & 0.384 & 0.272 \\
Mean dep var & 41,157 & 0.217 & 0.0983 \\
\hline
\end{tabular}

Notes: An observation is a sales agent. Standard errors clustered by division are reported in parentheses. Controls for prior sales, agent type, and county fixed effects are included. Sales Premiums Collected are in Kenyan Shillings. * significant at 10\%; ** significant at 5\%; *** significant at $1 \%$

Figure 5: Agent Premiums Collected Comparison by Agent Ability

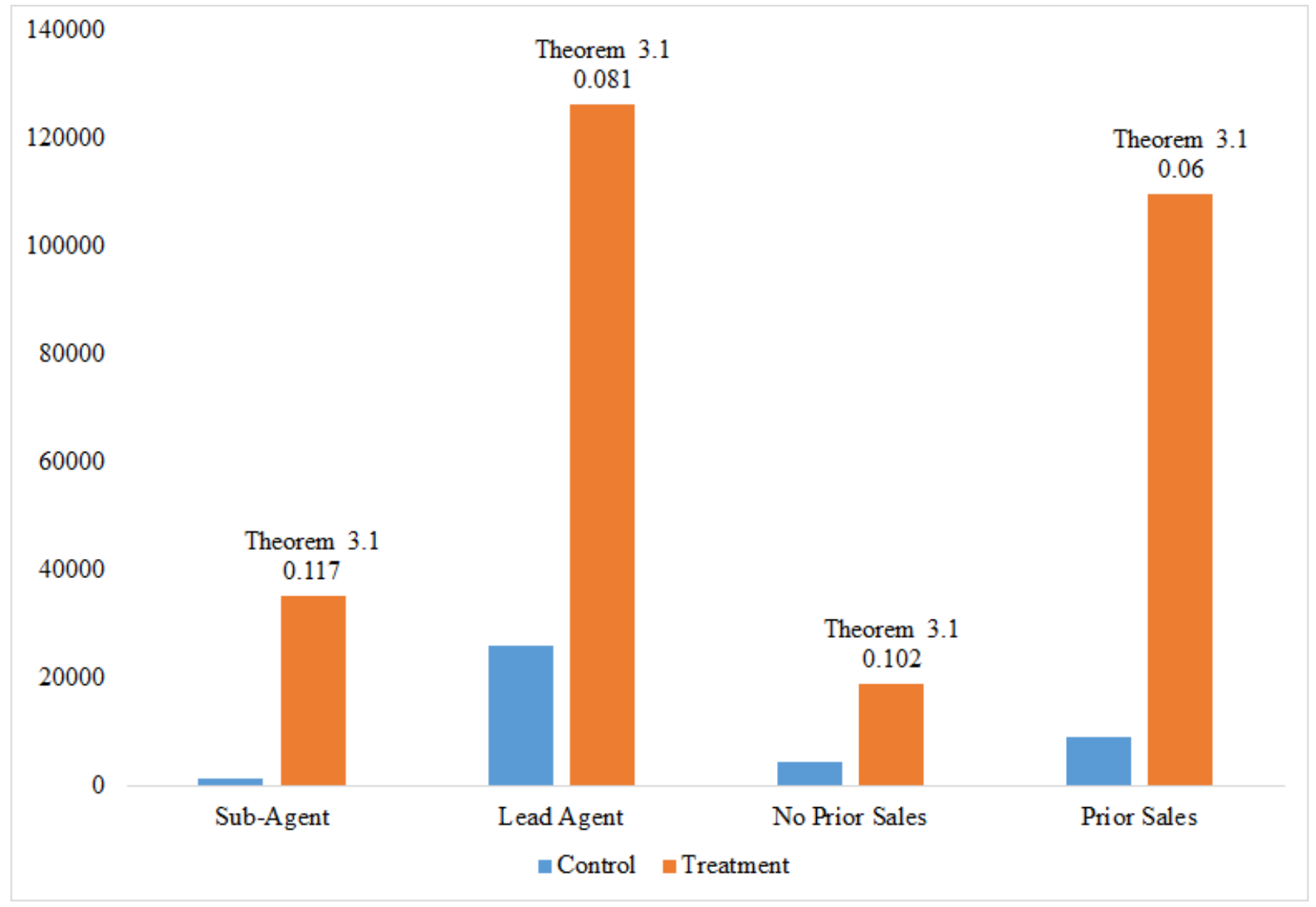


Table 7: Effect of Access to Training on Sales by Agent Ability

\begin{tabular}{|c|c|c|}
\hline VARIABLES & $\begin{array}{c}(1) \\
\text { By Agent Type }\end{array}$ & $\begin{array}{c}(2) \\
\text { By Sales Experience }\end{array}$ \\
\hline Training Access Treatment & $\begin{array}{c}6,309.392 \\
(9,553.004)\end{array}$ & $\begin{array}{c}5,116.423 \\
(7,622.447)\end{array}$ \\
\hline Agent Type & $\begin{array}{c}21,770.105 \\
(13,289.289)\end{array}$ & \\
\hline Agent Type* & $49,083.289 * *$ & \\
\hline Training Access Treatment & $(19,613.719)$ & \\
\hline Any Prior Sales & & $\begin{array}{c}-36,006.600^{* *} \\
(15,478.366)\end{array}$ \\
\hline Any Prior Sales* & & $52,298.864 * * *$ \\
\hline Training Access Treatment & & $(15,718.662)$ \\
\hline $\begin{array}{l}\mathrm{H}_{o} \text { : Training Access Treatment+Agent Ability } \\
+ \text { Training Access Treatment*Agent Ability }=0\end{array}$ & $0.000 * * *$ & $0.031 * *$ \\
\hline Observations & 295 & 295 \\
\hline R-squared & 0.288 & 0.289 \\
\hline Mean dep var & 20,418 & 20,418 \\
\hline
\end{tabular}

Notes: An observation is a sales agent. Standard errors clustered by division are reported in parentheses. Controls for prior sales and county fixed effects are included in column 1, controls for agent type, and county fixed effects are included in column 2. Sales Premiums Collected are in Kenyan Shillings. The $\mathrm{H}_{o}$ : Training Access Treatment+Agent Ability+ Training Access Treatment*Agent Ability $=0$ row reports the $\mathrm{p}$-values of this test. * significant at $10 \%$; ** significant at $5 \%$; *** significant at $1 \%$

Table 8: Effect of Access to Training on Sales by Agent Ability and Incentives for Training Investment

\begin{tabular}{lcccc}
\hline & $(1)$ & $(2)$ & $(3)$ & $(4)$ \\
VARIABLES & Sub-Agent & Lead Agent & No Prior Sales & Prior Sales \\
\hline \multirow{3}{*}{ Basic Treatment } & $5,751.346$ & $45,173.755$ & $5,181.801$ & $68,790.039^{* *}$ \\
& $(5,685.138)$ & $(28,368.001)$ & $(5,081.844)$ & $(33,165.042)$ \\
Incentive Treatment & $23,731.506$ & $54,200.865$ & $19,010.363$ & $76,815.941^{* *}$ \\
& $(19,347.391)$ & $(35,153.901)$ & $(15,954.742)$ & $(33,705.999)$ \\
Competition Treatment & $-1,782.010$ & $70,547.125^{* *}$ & $-2,089.353$ & $58,377.733^{* *}$ \\
& $(10,898.211)$ & $(33,294.270)$ & $(7,018.363)$ & $(23,942.484)$ \\
Observations & 241 & 54 & 203 & 92 \\
R-squared & 0.111 & 0.595 & 0.151 & 0.412 \\
Mean dep var & 9,874 & 67,478 & 10,088 & 43,213 \\
\hline
\end{tabular}

Notes: An observation is a sales agent. Standard errors clustered by division are reported in parentheses. Controls for prior sales and county fixed effects are included in columns 1 and 2, controls for agent type, and county fixed effects are included in columns 3 and 4. Sales Premiums Collected are in Kenyan Shillings. * significant at 10\%; ** significant at 5\%; *** significant at $1 \%$ 